\section{Exploring communication skills training in undergraduate nurse education by means of a curriculum}

\author{
Britt-Maj Wikström, ${ }^{1,2}$ Gunilla Svidén ${ }^{3}$ \\ 'Akershus University College, \\ Department of Health, Nutrition and \\ Management; 'Karolinska Institute, \\ Department of Public Health Sciences, \\ Stockholm; ${ }^{3}$ Linköping University, \\ Department of Communication, Sweden
}

\section{Abstract}

This study is an attempt to investigate by means of a curriculum how nurses are trained theoretically and practically throughout their specialist education to communicate competently and professionally in interaction with colleagues and patients. Research today shows that there are many different approaches to develop professionally skilled communication in nurse-patient interaction. It indicates that this aspect of nurse education is regarded as an important feature by educators. It is therefore of interest to study, by means of analysing a curriculum, how nurses' communicative competence is developed. To this purpose a curriculum was presented related to nursing communication skills training, selected from a University College of Health Care Sciences in Sweden. Both students and teachers need clearly defined curricula to structure their studies and to evaluate communication skills. The investigated curriculum could be further developed to direct students and teachers in effective communication skills. It is of importance to have a curriculum that could be interpreted in the same way by teachers and students.

\section{Introduction}

This study was to investigate how nurses are trained theoretically and practically throughout their specialist education to communicate competently and professionally with colleagues and patients, with an examination of the curriculum. According to a socio-cultural perspective as the individual becomes exposed to new and more specialized forms of social practices he/she will perceive and handle reality in qualitatively new ways. ${ }^{1-6}$ Nursing education is one example of a new socio-cultural context in which the students become exposed. The individual's socio-cultural background, unique experiences and knowledge constitute a fundamental frame of reference for the individual's perception of the surrounding world. This line of reasoning is important because of the educational implications. ${ }^{7-8}$ Conditions in the context constitute factors which mediate in the individuals' use of different modes of reflection and strategies for action. Communication in interaction in nursing provides opportunities to develop inter personal skills which are adapted to different interaction goals.

There is a large and diverse body of literature that deals with the development of communication skills. Different resources for teaching and learning communication skills within nursing education have been widely used, including videotapes of role-plays with simulated patients. As different methods have been used for training as well as a variety of methods for evaluation it is not possible to compare the strategies in different training programs. However, there are many theoretical concepts which could be used to promote development of communication skills, both from a structural as well as practical point of view. ${ }^{9}$

Thus, it is of interest to study, by means of a curriculum, how student nurses are educated and trained regarding person-centred communication skills in interaction with patients and colleagues.

\section{Theoretical Framework}

\section{The sociology of communication}

The starting point of this study is that all human knowledge is developed, transmitted and maintained in social situations. The sociology of knowledge must seek to understand the processes by which this is done. ${ }^{10}$

From a sociological point of view, reality and knowledge are initially justified by the fact of their social reality. What is real to a Tibetan monk may not be real to an American businessman. The knowledge of the criminal differs from the knowledge of the criminologist. ${ }^{11}$ It follows that specific aspects of reality and knowledge pertain to specific social contexts. ${ }^{12}$

We deal with other people and acquire many concepts, ideas and ways of thinking through formal instruction, through shared experience and through conversation. But it does not follow that we acquire a coherent system of thought that makes it possible to talk about which conceptions are common in a certain population.

Social behaviour can be regarded as a skilled performance which is an integral part in social interaction. This approach is of special importance in certain professions such as the health care professions. Thus, social interaction can be used to give information regarding an individual's degree of professional
Correspondence: Britt-Maj Wikström, Faculty of Health Sciences 0slo and Akershus University College of Applied Sciences, Postbox 4, St. Olovsplass 0130 0slo, Norway.

Tel. + 47.648.492.37

E-mail: britt-maj.wikstrom@hiak.no

Key words: communication, nurse education, curriculum, case study.

Received for publication: 23 August 2011. Accepted for publication: 28 October 2011.

This work is licensed under a Creative Commons Attribution NonCommercial 3.0 License (CC BYNC 3.0).

(C) Copyright B.M. Wikström and G. Svidén, 2011 Licensee PAGEPress, Italy

Nursing Reports 2011; 1:e7 doi:10.4081/nursrep.2011.e7

social skills. It is important for the nurse to establish and maintain a good relationship with the patient. A certain social skills have been found to be related to patients' satisfaction, for example, when the doctor is warm and friendly, gives reassurance, expresses sympathy and understanding, and discovers and deals with patients' concerns and expectations. ${ }^{13}$

\section{Effective elements in the psychotherapeutic communication}

Similarly, psychotherapy research has been directed towards discovering and isolating the effective elements in the psychotherapeutic process that lead to a constructive change in the patient. ${ }^{14-16}$ According to Truax and Carkhuff (1967), the therapist has to develop interpersonal skills to the point where he/she can effectively communicate high levels of non-possessive warmth, genuineness and accurate empathic understanding. These characteristics are described as; an effective therapist is integrated, non defensive, and authentic or genuine in his therapeutic encounters; an effective therapist can provide a non-threatening, safe, trusting or secure atmosphere by his acceptance, unconditional positive regard, love, or non possessive warmth for the client; an effective therapist is able to be "be with", "grasp the meaning of", or accurately and empathically understand the client on a moment-by moment basis. ${ }^{17}$

\section{Health professionals' communication with patients}

Health professionals need to attend to both biomedical aspects of disability as well as the illness experience. Understanding the experience of living in a disabled body is central to understanding the patient's life world. ${ }^{18}$ Thus, observations of the behaviour and actions of 
the patient need to be interpreted by the health professional in order to enter the patient's life world and to establish a collaborative process with the patient. Health professionals must form alliances with their patients so that the patients will do with the health professionals in order to ultimately become independent and to do for themselves to engage the patient's active collaboration in her/his treatment.

It is a fact well known that in the Rogerian school of psychotherapy, it is regarded as most important that the health care professional enables the patient to formulate/verbalize experiences and feelings in order to gain insight, and also that the patient is free to select which aspects are of importance and which are less of less importance. ${ }^{15}$ It is of importance for health care professionals to be able to express acceptance of the patient's point of view and to express comments generated toward helping the patient to awareness and to understand different reactions.

Health care professionals and social workers are required to form opinions about clients' dispositions, attitudes or emotional strategies within a very short time. Such assessment is necessary to decide a client's suitability for a particular type of treatment; ability to actively collaborate in treatment or understand information, as well as to gain insight into clients' emotional and motivational states and requires a phenomenological approach. Nurses are required to communicate on different levels; to give and gather information; to support; to question; to encourage; and to confront. To communicate refers to a two way process, and has emotional as well as cognitive aspects. Nurses are required to alternate between different communicative approaches related to different interactional goals. ${ }^{9}$

As has been described above there are many different approaches to the development of professionally skilled communication in nursepatient interaction. This indicates that this aspect of nurse education is regarded as an important feature by educators. It is therefore of interest to investigate, by means of a analysing a curriculum, how communication skills are expressed.

\section{The essence of reflection}

The essence of reflection on reflection-in action is hearing or seeing differently, a process which is called reframing. Although each patient reacts in his/her individual way to physical problems, illness, trauma and handicap which require an individualized approach, it also involves focusing on common elements which are of significance for the understanding of a particular diagnostic group of patients. This implies that professionals develop a framework for typifying/classifying individual patients. Such a framework enables professional co-members to communicate with each other in a manner where certain features can be taken for granted as they refer to common ground, theoretical and practical, shared by members, and to convey to each other what is regarded as significant facts in relation to their professional activities. Thus health professionals need to have at her/his disposal a framework for analyses which goes beyond that which the layperson uses for everyday life. Person-centred communication refers to behaviour reflecting awareness of an adaptation to subjective, affective and relation aspects. ${ }^{19-21}$ The development of a reflective practitioner is fundamental in many nursing programs. In spite of this new lecturers perceived lack of reflection in the curriculum and strategies used in teaching reflection. It is suggested that new lectures need more preparation in the skill of reflection. ${ }^{22}$

\section{How to assess communication skills training in nursing education}

Evaluating nursing communication skills training is a vital component of student nurses' education. Nurses often lack effective communication with patients and health care providers. They show that neither self-rated ability nor satisfaction was correlated with the objective measure of performance. ${ }^{23}$

Training in communication has been found to lead to improved patient outcome. However, to lead to improvements, training must be both participatory and experiential. A confounding factor in assessing the efficacy of communication program is that of outcome measurement. There is little consensus on how to best assess the success of communication skills training, because assessment methodologies demonstrate a high degree of variability. Real life measuring communication skills in medical settings with real patients is successful. ${ }^{24}$

In order to identify the most appropriate methods of assessment, and allow for a comprehensive assessment of the efficacy of communication skills training for student nurses, it is important to investigate the relationship between outcome measurements. Student satisfaction and self-rated ability are commonly used in evaluation of communication skills training. However, little research has been conducted investigating the links between these outcomes in the context of student nurse communication training. ${ }^{25}$

\section{Objectives}

The aim of the present study is to investigate, by means of a curriculum, how nurses during their education are trained and prepared for verbal communication with colleagues, patients and their relatives.
An important point is the notion that the categories that we employ in thinking are social and inherited. ${ }^{12,26}$ It is based on the individual's socio-cultural background and unique experiences. A frame of reference for perception of the surrounding world, such as knowledge, is fundamental and a base in the thinking process.

A period of time spent in nursing education should provide an institutional environment for the development of new and more specialized forms of perceiving and handling communication in social interaction. It is therefore of interest to study, by means of a curriculum, how students' learning in communication skills could be developed.

\section{Study Methods}

\section{Study approach}

The study was to investigate a curriculum that constitutes base in undergraduate nurse education and explore its adequacy for communication skills training.

\section{Study design}

The curriculum studied was representative to the nurse education communication program in nursing divisions in the colleges of health sciences in Sweden. The criteria presented in the nursing program curriculum framework, goals and structure, will be studied for its accuracy to provide guidelines for students and teachers to relay on for learning and teaching communication skill. A communication skills program in a curriculum for student nurses in the first, second and third study year was selected. They were then analyzed according to its relevance and structure to guide students and teachers in communication skills training.

\section{Data Collection}

Data were collected by a random selection procedure of one University College of Health Care Sciences in Sweden. From this university college, communication skills training component in the nursing program curriculum was then chosen. With this purpose, we extracted from curricula the contents related to communication skills program in a three-year undergraduate programme that leads to professional nurse registration and an undergraduate degree in nursing. The selected program was regarded as representative for nursing education in Sweden. 


\section{Communication skills program; student nurses first study year}

The students were introduced to a phenomenological approach according to the literature in the curriculum in order to analyse and discuss everyday communication. ${ }^{27-29}$ These discussions were taped in order to be analysed by the students.

The criteria presented in this nursing program curriculum framework contain various aspects of the course. However, the goals and structure presented in the curriculum do not provide guidelines in behavioural terms for students to relate to in their communication training. The goal presented was to promote the good meeting and the value of communication in nursing care. Assessment and learning outcomes and clear goals are not presented in the curriculum.

\section{Communication skills program; student nurses second study year}

The students' role plays interviews taking the part of nurse, patient and relatives. These role played interviews are videotaped to facilitate students' insights into their performances. The students show the videotaped interviews to their fellow students who are supposed to look at, and reflect on these critically. Each group of students $(\mathrm{n}=4-5)$ have at their disposal 40 minutes. Within this time the production/performance of the videotape is included.

\section{Communication skills program; student nurses third study year}

The students were required to reflect on and analyse the audio- and video tapes which they participated in during their first and second year. These reflections should be related to literature studies. The aim was to extend the understanding of communication skills in nursing situations.

\section{Discussion}

A curriculum as a base for undergraduate communication skills program was central in the present study. The pedagogy in use in nurse education must continually be questioned and expanded. It is a vital component of student nurses' education. Student nurses must be prepared for nursing practice that continually changes, meaning that alternative concepts in nurse education must be considered. ${ }^{30}$ Nurses often lack effective communication with patients and health care providers. Neither self-rated ability nor satisfaction was correlated with the objective measure of performance as this was a qualitative study. ${ }^{23}$ Evaluating nursing communication skills training is a vital component of student nurs- es' education. In the studied curriculum this aspect is not explicitly expressed.

When investigating about the present curriculum, it was not explicitly expressed that students' communicative abilities should be assessed before as well as after the training sessions.

In addition, it was not stated which communicative behaviors student nurses needed to develop and demonstrate during the communication skills training.

Therefore, this aspect of nurses' education cannot be effectively estimated.

The ability to act on the basis of situational appropriate cues, to reflect, to construe different hypotheses at a thematic as well as on an individual level is a characteristic quality of the reflective practitioner which has been pointed out by many researchers on clinical reasoning. ${ }^{20-21}$ The development of a reflective practitioner is fundamental in many nursing programs. However, according to research, new lecturers perceive lack of reflection in the curriculum as well as strategies to be used in teaching reflection. ${ }^{22}$ This is in line with the studied curriculum in the present study. The findings reported here indicate that this aspect of clinical reasoning is not present in relation to communication skills training and thus suggesting that an increased educational focus may be needed.

A theoretical starting point e.g. a phenomenological approach should provide a framework for assessing patients in general terms from several perspectives i.e. physical, social, emotional and intellectual.

Most of the daily interaction between people is dependent upon the ability to perceive other people's feelings, attitudes, and motives. Strategies that are appropriate for assessing the needs of different patients as well as different situations need to have a theoretical approach. The construction of social reality, a necessary and sufficient condition towards effective person centered communication. Each patient reacts in her individual way to physical problems. This implies to develop a framework for typifying individual patients that is based in a theoretical framework.

As individuals vary in their expression of emotions, there is no one-to-one relationship between non verbal cues and emotions. The same behavior may be related to a variety of emotions. Furthermore, the same emotion may be expressed nonverbally in different ways, depending on personality, sex, age, upbringing, social class, and situation.

Most of the daily interaction between people is dependent upon the ability to perceive other people's feelings, attitudes, and motives. Strategies that are appropriate for assessing the needs of different patients as well as different situations need to have a theoretical approach. The construction of social reality, a necessary and sufficient condition towards effective person centered communication. Each patient reacts in her individual way to physical problems. This implies to develop a framework for typifying individual patients that is based in a theoretical framework.

As individuals vary in their expression of emotions, there is no one-to-one relationship between non verbal cues and emotions. The same behavior may be related to a variety of emotions. Furthermore, the same emotion may be expressed nonverbally in different ways, depending on personality, sex, age, upbringing, social class, and situation.

As has been pointed out above, conditions in the cultural context e.g. nursing training constitute factors which mediate in the individual's use of different modes of reflection and strategies for action. It is not only the quantities of time assigned to communication skills training, but it is also through interaction in the social world that individuals' develop interpersonal perspective skills and to use personcentred communication adapted to different interaction goals. Similar thinking is expressed in research by Parry ${ }^{24}$ who express that training must be both participatory and experiential to lead to improvements. In addition, there is little consensus on how to best assess the success of communication skills training, because assessment methodologies demonstrate a high degree of variability. ${ }^{24}$

A person-centered communication skills module should be included in the final year of the undergraduate nursing program in order to be better positioned to apply the skills of effective communication in practice. ${ }^{31}$ Students' self-rated ability are commonly used in evaluation of communication skills training ${ }^{25}$ This thinking points at the importance to have a curriculum that could guide teachers and students to achieve knowledge in communication skills with patients and their relatives.

It has to be pointed out that both students and teachers expressed a need for clearly defined aims expressed in the curriculum to direct the studies and evaluate the results of their communication skills. The results also show that the studied curriculum could not guide teachers and student nurses in a satisfactory manner. Further research is recommended to study existing curriculum for their precision to insure a high-quality communication skills training in nurse education so as to develop competent nursing practitioners.

\section{Conclusions}

From a practical point of view the student should be able to demonstrate interaction with different patients. They should also be able to apply communicative strategies which are rel- 
evant in different situations e.g. giving information, gathering information, giving support, obtain compliance and to confront some of the beliefs or values which are contra productive to the treatment. Finally, they should develop a repertoire of communicative strategies appropriate to different types of patients, interaction goals and situations to prevent stereotype communication. From the reasoning in the present study, both students and teachers need a clearly defined curriculum to direct students' nursing studies and evaluate their communication skills. This can help further develop the studied curriculum to support teachers and students in learning.

\section{References}

1. Säljö R, Wyndham J. Conceptual knowledge in talk and text. Instruct Sci 2001;29:213-36.

2. Säljö R. Learning in educational settings: methods of inquiry. In: Ramsden P, editor. Improving learning. New perspective. pp. 32-48. London: Kogan Page; 1988.

3. Wertsch JV. Culture, communication and cognition. New York: Cambridge University Press; 1985.

4. Vygotsky LS. Thought and language. (Translated by A Kozulin). Cambridge; The MIT Press: 1968.

5. Searle JR. The construction of social reality. Middlesex, England: The Penguin Books Ltd Harmondsworth; 1995.

6. Rust J. John Searle and the construction of social reality. New York: Continuum Studies in American Philosophy; 2006.

7. Morgan S, Dennehy RF. Using stories to reframe the social construction of reality: A trio of activities. J Manage Educ 2004;28:372-89.

8. Bohm D. Thoughts as a system. London:
Routledge; 1992.

9. Wondrak R. Skills for nurses and health care professionals. London: Blackwell Science Ltd: 1998.

10. Potter J. Representing reality, discourse, rhetoric and social construction. London: Sage Publication; 1996.

11. Berger P, Luckman T. The social construction of reality, a treatise in the sociology of knowledge. New York: Anchor Books, Random House, Inc; 1967.

12. Bless H, Fiedler K, Strack F. Social cognition; how individuals construct social reality. New York: Psychology Press, Taylor \& Francis Group; 2004.

13. Argyle M. The psychology of interpersonal behaviour. Harmondsworth, Middlesex, England: Penguin Books; 1994.

14. Shoben EJ. Some observations on psychotherapy and the learning process. In Mowrer $\mathrm{OH}$, editor. Psychotherapy: Theory and research. New York: Ronald Press; 1953.

15. Rogers CR. The necessary and sufficient conditions of therapeutic personality change. J Consult Psychol 1957;21:95-103.

16. Ricoeur P. Oneself as Another. (Translated by K. Blamey). London: The University of Chicago Press; 1990/1992.

17. Truax CB, Carkhuff RR. Toward effective counselling and psychotherapy. Chicago Illinois: Aldine Publishing Company; 1967.

18. Schuster M. Profession och existens. (Profession and existence). En hermeneutisk studie av asymmetri och ömsesidighet i sjuksköterskans möten med svårt sjuka patienter. Göteborg: Bokförlaget Daidalos AB; 2006.

19. Schön DA. The reflective practitioner: How professionals think in action. London: Temple Smith; 1983.

20. Schön DA. Educating the reflective practitioner. San Francisco: Jossey-Bass; 1987.

21. Schön DA. The reflective turn: Case stud- ies in and on educational practice. New York: Teachers College; 1991.

22. Braine ME. Exploring new nurse teachers' perception and understansing of reflection: An exploratory study. Nurse Educ Pract 2009;9:262-70.

23. Mullan BA, Kothe EJ. Evaluating a nursing communication skills training course: The relationships between self-rated ability, satisfaction, and actual performance. Nurse Educ Pract 2010;10:374-78.

24. Parry R. Are intervention to enhance communication performance in health professionals effective, and how should they be delivered? Direct and indirect evidence. Patient Educ Counsel 2008;73:186-95.

25. Farrel GA, Cubit KA, Bobrowski CL, Salmon P. Using the WWW to teach undergraduate nurses clinical communication. Nurse Educ Today 2007;27:427-35.

26. Jaspers K. Philosophy. Vol. 2, Transl. EB Ashton. (Orginally Published in 1932 as Philosophie by Springer - Verlag, BerlinGöttingen-Heidelberg). Chicago/London: The University of Chicago Press; 1970.

27. Marton F. Phenomenography describing conceptions of the world around us. Instruct Sci 1981;10:177-200.

28. Marton F. Phenomenography and "the art of teaching all things to all men". J Qual Stud Educ 1992;5:253-67.

29. Eide H, Eide T. Omvårdnadsorienterad kommunikation. (Communication in nursing). Lund: Studentlitteratur: Lund; 1999.

30. Argyris, C, Schön D. Theory in practice: Increasing professional effectiveness. San Francisco: Jossey-Bass; 1974.

31. McCarthy B, O’Donovan M, Twomey A. Person-centered communication: Design, implementation and evaluation of a communication skills module for undergraduate nursing students - an Irish context. Contemp Nurse 2008;27:207-22. 